\title{
Smoking and psychiatric disorders: a comorbidity survey
}

F.L. Lopes ${ }^{1}$,

I. Nascimento ${ }^{1}$, W.A. Zin ${ }^{2}$,

A.M. Valença ${ }^{1}$,

M.A. Mezzasalma',

I. Figueira ${ }^{1}$ and A.E. $\mathrm{Nardi}^{1}$

\author{
Laboratórios de 1Pânico e Respiração, Instituto de Psiquiatria, and \\ ${ }^{2}$ Fisiologia da Respiração, Instituto de Biofísica Carlos Chagas Filho, \\ Universidade Federal do Rio de Janeiro, Rio de Janeiro, RJ, Brasil
}

\section{Correspondence}

F.L. Lopes

Laboratório de Pânico e Respiração

Instituto de Psiquiatria, UFRJ

R. Visconde de Pirajá, 407/702

22410-003 Rio de Janeiro, RJ

Brasil

Fax: + 55-21-2523-6839

E-mail: aenardi@ novanet.com.br

Research supported by CNPq

(No. 300500/93-9).

$\ldots \ldots \ldots \ldots \ldots \ldots$

Received August 30, 2001

Accepted June 18, 2002

\section{Abstract}

Epidemiological and clinical studies have shown a positive correlation between smoking and psychiatric disorders. To investigate the prevalence of cigarette smoking, 277 psychiatric outpatients with anxiety or depressive disorders (DSM-IV) answered a self-evaluation questionnaire about smoking behavior and were compared with a group of 68 control subjects. The diagnoses $(\mathrm{N}=262)$ were: $30.2 \%$ $(\mathrm{N}=79)$ major depressive disorder, $23.3 \%(\mathrm{~N}=61)$ panic disorder, $15.6 \%(\mathrm{~N}=41)$ social anxiety disorder, $7.3 \%(\mathrm{~N}=19)$ other anxiety disorders, and $23.7 \%(\mathrm{~N}=62)$ comorbidity disorders. Among them, $26.3 \%(\mathrm{~N}=69)$ were smokers, $23.7 \%(\mathrm{~N}=62)$ were former smokers and $50.0 \%(\mathrm{~N}=131)$ were nonsmokers. The prevalence of nicotine dependence among the smokers was $59.0 \%$ (DSM-IV). The frequency of cigarette smoking did not show any significant difference among the five classes of diagnosis. The social anxiety disorder patients were the heaviest smokers $(75.0 \%)$, with more unsuccessful attempts to stop smoking $(89.0 \%)$. The frequency of former smokers was significantly higher among older subjects and nonsmokers were significantly younger $\left(\chi^{2}=9.13\right.$, d.f. $\left.=2, P=0.01\right)$. Our data present some clinical implications suggesting that in our psychiatric outpatient sample with anxiety disorder, major depression and comorbidity (anxiety disorder and major depression), the frequency of cigarette smoking did not differ from the frequency found in the control group or in general population studies. Some specific features of our population (outpatients, anxiety and depressive disorders) might be responsible for these results.

\section{Introduction}

Smoking has been referred to as the most important preventable cause of death and disease $(1,2)$. It is responsible for $20 \%$ of all deaths in the USA, and $45 \%$ of smokers will die of a tobacco-induced disorder (3). Cigarette smoking causes several clinical pathologies such as lung cancer and chronic obstruc-

\section{Key words} - Smoking

- Panic disorder

- Social anxiety disorder

- Depression

- Depressive disorder 
significant decline of the prevalence of smoking in the general population of the United States (4), although clinical studies have shown a higher frequency of smoking among psychiatric patients than among control groups (52 versus $30 \%$ ) (5). Psychiatric predictors of initiation of smoking include use and abuse of alcohol and other drugs, major depressive disorder, anxiety disorders, adult attention deficit hyperactivity disorder and bulimia/binge-eating (2,5-7).

The influence of smoking among psychiatric patients has some clinical implications. Smoking can improve cognition, mood and anxiety (5) by the multiplicity of positive reinforcing effects of nicotine (8) and nicotine withdrawal can exacerbate these symptoms $(2,5)$. Nicotine withdrawal may also aggravate some psychiatric disorders, cause relapse, mimic or worsen side effects, and increase blood levels of several medications (2). Most smokers make several unsuccessful attempts to stop smoking (2). Smokers with a past or present history of anxiety or depression are less likely to stop smoking $(2,6)$. A relationship between smoking and major depressive disorder $(9,10)$ suggests a continuity of smoking behavior among depressive subjects. More recent studies have reported a closer relationship between smoking and anxiety disorders $(11,12)$. There is good evidence for a causal relationship between smoking and the first panic attack $(13,14)$.

The natural history of smoking initiation and cessation has been quite well described for the general population (2). However, similar studies on psychiatric patients are lacking (2). We have investigated the prevalence of smoking in a sample of patients with depression or anxiety disorders. The objectives were to observe and to compare in each diagnostic group a) frequency of smoking, b) daily cigarette consumption, the attempts to stop smoking and the frequency of nicotine withdrawal syndrome, and c) the influence of nicotine on anxiety and/or depressive symptoms.

\section{Patients and Methods}

We conducted a cross-sectional retrospective study on a sample of outpatients referred to the Outpatient Clinic, Institute of Psychiatry, Federal University of Rio de Janeiro (IPUB, UFRJ). A total of 277 subjects were selected at random from May through August 1999, including consecutive outpatients seen for routine consultation or for the first time at the anxiety unit of IPUB, UFRJ. A group of 68 adult individuals with no previous or current history of anxiety or major depressive disorders (45 women and 23 men, mean age \pm SD: $35.1 \pm 10.43$ years) was used as control. The study protocol was approved by the Ethics Committee of IPUB, UFRJ. After a complete description of the study to the subjects, written informed consent was obtained. The criteria for inclusion in the study were male or female individuals aged at least 18 years and presenting a major depressive and/or anxiety disorder at the time of the interview.

The psychiatric diagnosis was made using the Structured Clinical Interview (SCID-I) (15) for DSM-IV (16). The subjects were grouped into five main diagnostic categories. Those with more than one disorder were assigned to the category of comorbidity disorders. The other categories were depressive disorder, panic disorder, social anxiety disorder, and other anxiety disorders.

The comparison group was also assessed by the SCID (15). The subjects in this group were free of any history or of current panic disorder, major mood disorder, schizophrenia, or current non-nicotine substance use disorders.

The subjects answered a standard selfevaluation questionnaire about smoking behavior while they waited for medical attendance. When difficulties arose, a research assistant who had a bachelor's degree and two years of clinical experience provided help.

The questionnaire contained 16 items related to smoking habits, definition of regular 
use, nicotine withdrawal symptoms and attempts to stop smoking. Smoking behavior was assessed according to patterns of duration of cigarette use, number of cigarettes per day, if the patient judges it difficult to refrain from smoking in forbidden places, or if the patient wakes up during the night to smoke and at which time of day the patient feels it is more difficult to give up smoking. Regular use was defined as daily use during a period of at least 4 weeks. We analyzed the following items of the questionnaire: 1) frequency of smoking, 2) number of cigarettes, 3) attempts to stop smoking, 4) withdrawal symptoms, 5) distress or impairment of daily activities caused by withdrawal symptoms, and 6) interference of smoking with anxiety or depression symptoms.

For number of cigarettes/day, the subjects rated themselves on a six-point scale as follows: 1) smoked 1 to 3 cigarettes/day, 2) smoked 4 to 10 cigarettes/day, 3) smoked 11 to 20 cigarettes/day, 4) smoked 21 to 30 cigarettes/day, 5) smoked 31 to 40 cigarettes/day, and 6) smoked more than 41 cigarettes/day. Because of the small number of subjects in the heaviest smoking category, they were combined with those of the next highest group for most analyses. We divided the sample into nonsmokers, "exposed" (subjects who have smoked in their lifetime) and "regular" smokers (those who fulfill the definition of regular use and were still smoking at the time of the interview). "Light smokers" were considered to be those who regularly smoked 10 or fewer cigarettes per day.

Nicotine withdrawal was considered "severe" when four or more symptoms were present after the individual stopped smoking, according to the classification criteria of the DSM-IV (17).

DSM-IV criteria were used to assess dependence among all respondents. We considered dependent regular smokers those respondents who smoked cigarettes daily for a period of 4 weeks or more and who met DSM-IV criteria for nicotine dependence.

\section{Statistical analysis}

The Epi Info Program, version 6.04, was used for data analysis (CDC, OMS, 1997). Comparative analysis was performed by the chi-square test with Yates correction, with the level of significance set at $\mathrm{P}<0.05$.

\section{Results}

Fifteen subjects were excluded from the initial psychiatric sample $(\mathrm{N}=277)$ because they did not fulfill the diagnostic criteria for depressive or anxiety disorder. The final sample $(\mathrm{N}=262)$ included 163 women $(62.2 \%)$ and 99 men (37.8\%) aged 18 to 72 years (mean $\pm \mathrm{SD}: 39.7 \pm 10.7$ years). Half of the sample $(\mathrm{N}=131)$ had never smoked a cigarette, but only $26.3 \%(\mathrm{~N}=69)$ were regular smokers and $23.7 \%(\mathrm{~N}=62)$ were former smokers. The frequency of regular smokers in the major depressive and anxiety disorder categories did not differ significantly from the results obtained for the comparison group $(\mathrm{N}=68)$, which consisted of $23.5 \%(\mathrm{~N}=16)$ regular smokers, $20.6 \%(\mathrm{~N}=$ 14) former smokers, and $54.4 \%(\mathrm{~N}=37)$ nonsmokers ( $\mathrm{P}=0.756$, Fisher exact test). Forty-five women $(66.2 \%)$ and 23 men (33.8\%) (mean age: $35.1 \pm 10.43$ years) were used as the control group.

In the group of regular smokers (26.3\%), $59 \%$ fulfilled the DSM-IV criteria for nicotine dependence. Although social anxiety disorder tended to show an increased rate, it was not statistically significant (21.9 vs $14.7 \%$, social anxiety disorder $v s$ panic disorder; $\mathrm{P}=0.429$ ).

We divided the subjects into two groups according to age ( $\leq 39$ years and $\geq 40$ years) and observed that major depressive disorder was more frequent in individuals over 40 years of age. In contrast, panic disorder and other anxiety disorders were more frequent among younger individuals $\left(\chi^{2}=13.92\right.$, d.f. $=4, P=0.007)$. In the major depressive disorder category, $71.7 \%$ of women were 
over 40 years of age and $52 \%$ of men were younger ( $\leq 9$ years) (Mantel-Haenszel, $\chi^{2}=$ $4.09, \mathrm{P}=0.04$; Yates correction, $\chi^{2}=3.18$, $\mathrm{P}=0.07$ ).

No significant difference was found in the frequency of smoking among the five diagnostic categories (Table 1). However, the frequency of former smokers was significantly higher among older subjects and non-

Table 1. Profile of the patient sample in terms of cigarette smoking.

\begin{tabular}{lccrrr}
\hline & DD & PD & SAD & Others & CD \\
& N (\%) & N (\%) & N (\%) & N (\%) & N (\%) \\
\hline Smokers & $22(28)$ & $18(30)$ & $12(29)$ & $4(21)$ & $13(21)$ \\
Former smokers & $16(20)$ & $16(26)$ & $9(22)$ & $2(11)$ & $19(31)$ \\
Nonsmokers & $41(52)$ & $27(44)$ & $20(49)$ & $13(68)$ & $29(48)$ \\
\hline
\end{tabular}

The frequency of smoking did not differ among groups. Chi-square $=6.38$, d.f. $=8, P=$ 0.6. Diagnostic categories: DD - depressive disorder; PD - panic disorder; SAD - social anxiety disorder; Others - other anxiety disorders; CD - comorbidity disorders.

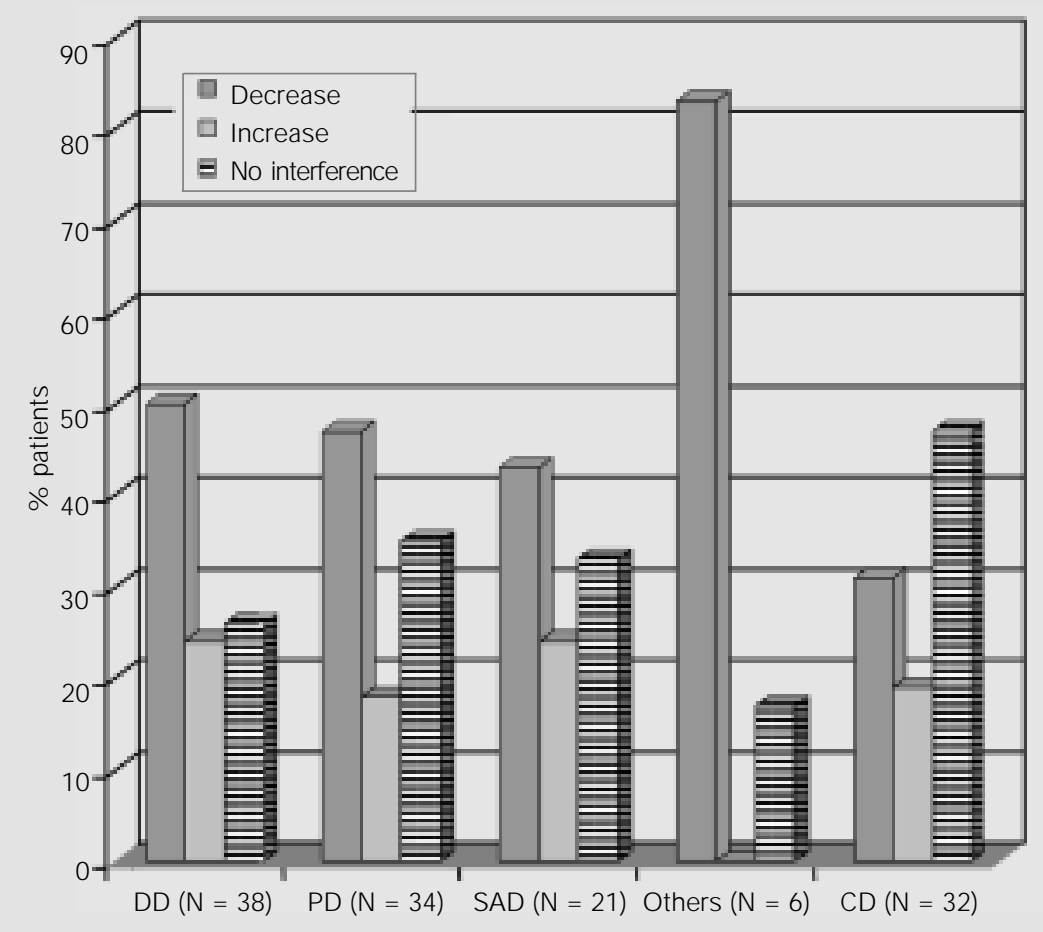

Figure 1. Percentage of patients in each psychiatric group answering how much (decrease vs increase vs no interference) smoking interferes with the psychiatric symptoms of their disorders. Chi-square $=8.05$, d.f. $=8, P=0.42$. For abbreviations see legend to Table 1 . smokers were significantly younger $\left(\chi^{2}=\right.$ 9.13 , d.f. $=2, \mathrm{P}=0.01)$. Among regular smokers there were no differences in relation to age. The frequency of smoking did not show any correlation with sex. The profile of the sample in terms of smoking habits is presented in Table 1.

When we compared the number of smoked cigarettes/day among the diagnostic categories, the most common average daily consumption was 11 to 20 . So, $\geq 11$ cigarettes/day was considered high $(\mathrm{N}=42)$, and $\leq 10$ cigarettes/day was considered low $(\mathrm{N}=27)$. Social anxiety $(75 v s 25 \%)$ and panic disorder subjects (66.7 vs 33.3\%) had a tendency to be heavier smokers than the subjects with major depressive disorder (50.0 vs 50.0\%) and the other diagnostic categories. However, this difference was not statistically significant $\left(\chi^{2}=2.55\right.$, d.f. $=4$, $\mathrm{P}=0.63$ ).

Comparing the number of unsuccessful attempts to stop smoking among "exposed" subjects, social anxiety subjects (88.9\%) had a tendency to higher scores than the subjects with major depressive disorder $(62.5 \%)$ and panic disorder $(62.5 \%)$. However, this difference was not statistically significant $\left(\chi^{2}=\right.$ 11.77 , d.f. $=7, \mathrm{P}=0.161$ ). These data were also not significantly different among regular smokers (66.7 vs 31.7 vs $24.4 \%$ for social anxiety disorder, major depression, and panic disorder, respectively) $\left(\chi^{2}=5.21\right.$, d.f. $=8$, $\mathrm{P}=0.734$ ).

The data for nicotine withdrawal symptoms were analyzed by a binary model (yes/ no). According to nicotine withdrawal severity criteria, subjects with panic disorder presented a tendency for more severe withdrawal symptoms than the subjects with major depressive and social anxiety disorder (50.0 vs $28.6 \%$ and $11.4 \%$, respectively) $\left(\chi^{2}=3.30\right.$, d.f. $\left.=4, \mathrm{P}=0.50\right)$, which, however, was not statistically significant.

A description of how smoking interferes with anxiety and/or depression is presented in Figure 1. 


\section{Discussion}

The frequency of smoking found in our study did not differ from that for the general population $(18,19)$, as supported by the similarity of the results for our psychiatric and comparison groups. Smoking prevalence surveys conducted in the United States (18) and in Latin American countries (19) have shown the same pattern of results. Silva and Koifman (19) demonstrated that Brazil, in 1998 , occupied second place for women $(25.4 \%)$ in the rank of smoking in Latin America. Giovino et al. (18) showed that $50 \%$ of the adult population of the United States have never smoked, $25 \%$ are regular smokers and $25 \%$ are former smokers. The similarity between our psychiatric and comparison groups supports these findings.

The lack of statistical significance between smokers and anxiety disorder patients and major depressive patients in the present study contradicts the results of Breslau et al. (17), who demonstrated that smokers with major depression were more than three times as likely to continue smoking as smokers with no history of major depression, and no anxiety disorder was related to the persistence of the smoking habit when major depression was controlled.

Sonntag et al. (12) investigated associations between social anxiety disorder and smoking behavior in order to explore whether social anxiety predicts the onset of cigarette smoking, regular smoking and the development of nicotine dependence. These investigators performed a cross-sectional retrospective baseline analysis $(\mathrm{N}=3021)$ and a prospective-longitudinal survey during a 4-year follow-up. Social anxiety disorder was significantly associated with nicotine dependence in both cross-sectional retrospective and prospective-longitudinal analyses. Some literature evidence supports a close relationship between social anxiety disorder and nicotine dependence and the comorbidity of both disorders with alcohol abuse/depend- ence (20-22). The consumption of alcohol by social anxiety disorder patients as a disinhibition factor with cognitive and biological characteristics has been well documented (23-25). A low $\mathrm{D}_{2}$ receptor binding potential has been reported in substance abuse disorders frequently in comorbidity with social anxiety disorder (21). Type I abstinent alcoholics also present increased $\left[{ }^{18} \mathrm{~F}\right]$-DOPA uptake in basal ganglia, suggesting that nicotine and alcohol dependence could share a similar mechanism related to dopamine (20).

A biological marker that sheds light on the reported evidence is a dopaminergic pathway of action related to nicotine $(20,26)$. Smoking has been linked to greater dopamine activity in the human basal ganglia $(20,26)$. As a central component of cigarette smoke, nicotine increases the release of dopamine in the smoker's striatum and consequently stimulates the presynaptic dopamine synthesis (20). Striatal monoamine oxidase $\mathrm{B}$ (MAO-B) levels are also reduced in smokers $(20,26)$. Therefore, more dopamine may be directed at the synthesis pathway rather than at the transformation into metabolites (20), since dopamine is partially metabolized in the brain by MAO-B. On the other hand, social anxiety disorder has been associated with a low dopamine $\mathrm{D}_{2}$ receptor binding potential in the striatum (21), in agreement with literature data showing low dopamine system activity in social anxiety disorder $(21,27)$. The development of nicotine dependence may be associated with increased dopamine activity in the basal ganglia $(20,26)$.

Fowler et al. (26) studied a sample of smokers by positron emission tomography in order to measure brain MAO-B levels after overnight cigarette abstinence $(11.3 \mathrm{~h}$ ) and observed that average MAO-B levels were $39 \%$ lower in smokers than in a comparison group of nonsmokers. Brain MAO-B levels did not differ between the overnight abstinence period and $10 \mathrm{~min}$ after smoking one cigarette among smokers. These data 
suggest long-lasting effects of nicotine dependence (26), which could be accountable for the increased rates of unsuccessful attempts to stop smoking in social anxiety disorder subjects.

There was no significant difference in the severity of nicotine withdrawal among the groups in our trial. Individuals with panic disorder were expected to present more severe nicotine withdrawal as explained by the cognitive model for panic disorder (28). It is well known that nicotine withdrawal can produce symptoms similar to those of a panic attack (anxiety, restlessness, heart rate change). The catastrophic interpretation of bodily sensations experienced during the withdrawal phase appears to play a central role in panic attacks (29). The erroneous interpretation of bodily sensations as dangerous and threatening may increase the anxiety symptoms, which in turn may lead to new sensations causing a progressive growth of symptoms and a greater severity of the DSMIV withdrawal criteria (16).

The panic disorder group tended to include the highest rate of former smokers (Table 1) and a lower number of unsuccessful attempts to stop smoking, different from the results found for the social anxiety group. These data support the anxiogenic properties of smoking (30). According to West and Hajek (30), smoking cessation is quite rapidly followed by a reduction in anxiety, suggesting the role of nicotine as an anxiogenic agent. The sensation of reduction in anxiety caused by smoking reported by the patients (Figure 1) can be explained by the initial positive reinforcing effects of stimulation and/or sedation induced by cigarette smok- ing $(8,31)$. It has been postulated that a quick tolerance develops (32) and the chronic use of smoking may lead to increased anxiety levels (30).

Smoller and Tsuang (33) consider psychological vulnerability to be a predisposing factor to nicotine dependence and major depression or anxiety disorders. Preliminary data (34) suggest an association of panic attacks with an increased risk of cigarette smoking among adults, and this relationship can only be evident in the presence of a high level of neuroticism. Goodwin and Hamilton (34) suggest that neuroticism may reflect a shared vulnerability to the co-occurrence of cigarette smoking and panic attacks.

We did not find specific withdrawal symptoms related to the diagnostic categories analyzed, in contrast to the findings of Breslau et al. (35) who observed a tendency towards dysphoria and depressive symptoms in individuals with major depression, and nervosism and restlessness in those with anxiety disorders.

Our data present some clinical implications suggesting that there is no significant difference between anxiety disorder patients, major depressive patients, comorbidity (anxiety and depression) and a control group. Some limitations should be mentioned such as the small size of the sample and the disadvantage of a retrospective study in terms of nicotine withdrawal, in which a bias of rationalization may be present. Thus, smokers may exaggerate the withdrawal symptoms to justify their incapacity to stop smoking. The classification into exposed and regular smokers was helpful to attenuate these discrepancies.

\section{References}

1. US Department of Health and Human Services (1990). Health Consequences of Smoking Cessation. A Report of the US Surgeon General. US Government Printing Office, Washington, DC, USA.
2. Hughes J R, Fiester S, Goldstein M, Resnick M, Rock N \& Ziedonis D (2000). Treatment of patients with nicotine dependence. In: American Psychiatric Association Practice Guidelines for the Treat- ment of Psychiatric Disorders. Compendium 2000. 1st edn. American Psychiatric Press, Washington, DC, USA.

3. Peto R, Lopez AD, Boreham J , Thun M \& Heath J r C (1992). Mortality from tobacco 
in developed countries: indirect estimation from national vital statistics. Lancet, 339: 1268-1278.

4. Fiore MC (1992). Trends in cigarette smoking in the United States: the epidemiology of tobacco use. Medical Clinics of North America, 76: 289-303.

5. Hughes J R, Katsukami DK, Mitchell JE \& Dahlgren LA (1986). Prevalence of smoking among psychiatric outpatients. American J ournal of Psychiatry, 143: 993-997.

6. Glassman AH (1993). Cigarette smoking: implications for psychiatric illness. American J oumal of Psychiatry, 150: 546-553.

7. Pomerleau CS (1997). Co-factors for smoking and evolutionary psychobiology. Addiction, 92: 397-408.

8. Wiseman EJ (1999). Cessation and anxiety. American J ournal of Psychiatry, 156: 336a.

9. Glassman $A H$, Helzer JE, Covey LS, Cottler LB, Stetner F, Tipp J E \& J ohnson J (1990). Smoking, smoking cessation, and major depression. J ournal of the American Medical Association, 264: 15461549.

10. Kendler KS, Neale MC, MacLean CJ, Heath AC, Eaves LJ \& Kessler RC (1993). Smoking and major depression: a causal analysis. Archives of General Psychiatry, 50: 36-43.

11. Amering M, Bankier B, Berger P, Griengl H, Windhaber J \& Katschnig H (1999). Panic disorder and cigarette smoking behavior. Comprehensive Psychiatry, 40: 3538.

12. Sonntag $H$, Wittchen $H U$, Hofler $M$, Kessler SC \& Stein MB (2000). Are social fears and DSM-IV social anxiety disorder associated with smoking and nicotine dependence in adolescents and young adults? European Psychiatry, 15: 67-74.

13. Pohl R, Yeragni $V \&$ Balon R (1992). Smoking in patients with panic disorder. Psychiatry Research, 43: 253-262.

14. Breslau N \& Klein DF (1999). Smoking and panic attacks: an epidemiologic investigation. Archives of General Psychiatry, 56: 1141-1147.

15. First MB, Spitzer RL, Williams J B \& Gib- bon M (1997). Structured Clinical Interview for DSM-IV - Clinician Version (SCIDCV). American Psychiatric Press, Washington, DC, USA.

16. American Psychiatric Association (1994). Diagnostic and Statistical Manual of Mental Disorders. 4th edn. American Psychiatric Press, Washington, DC, USA.

17. Breslau N, Kilbey $M M$ \& Andreski $P$ (1992). Nicotine withdrawal symptoms and psychiatric disorders: findings from an epidemiologic study of young adults. American J ournal of Psychiatry, 149: 464469.

18. Giovino GA, Henningfield JE, Tancer SL, Escobedo LG \& Slade J (1995). Epidemiology of tobacco use and dependence. Epidemiologic Reviews, 17: 48-65.

19. Silva VC \& Koifman S (1998). Tabagismo na América Latina: problema prioritário de saúde pública. Cademos de Saúde Pública, 14: 99-108.

20. Salokangas RK, Vilkman $H$, llonen $T$, Taiminen T, Bergman J, Haaparanta $M$, Solin O, Alanen A, Syvalahti E \& Hietala J (2000). High levels of dopamine activity in the basal ganglia of cigarette smokers. American J ournal of Psychiatry, 157: 632634.

21. Schneier FR, Liebowitz MR, Dargham AA, Ponce $Y Z$, Lin SH \& Laruelle M (2000). Low dopamine $D_{2}$ receptor binding potential in social phobia. American J ournal of Psychiatry, 157: 457-459.

22. Schneier FR, Martin LY, Liebowitz MR, Gorman J M, Klein DF \& Fyer AJ (1989). Alcohol abuse and social phobia. J ournal of Anxiety Disorders, 3: 15-23.

23. Thyer BA, Parrish RT, Himle J, Cameron OG, Curtis GC \& Nesse RM (1986). Alcohol abuse among clinically anxious patients. Behavior Research and Therapy, 24: 357-359.

24. Versiani M, Mundim FD, Nardi AE \& Liebowitz MR (1988). Tranylcypromine in social phobia. J oumal of Clinical Psychopharmacology, 8: 279-283.

25. Schneier FR, J ohnson J, Hornig CD, Liebowitz MR \& Weissman MM (1992). Social phobia. Comorbidity and morbidity in an epidemiological sample. Archives of General Psychiatry, 49: 282-288.

26. Fowler J S, Wang GJ, Volkow ND, Franceschi D, Logan J, Pappas N, Shea C, MacGregor RR \& Garza V (2000). Maintenance of brain monoamine oxidase $B$ inhibition in smokers after overnight cigarette abstinence. American J ournal of Psychiatry, 157: 1864-1866.

27. Tiihonen J , Kuikka J , Bergstrom K, Lepola U, Koponen H \& Leinonen E (1997). Dopamine reuptake site densities in patients with social phobia. American J ournal of Psychiatry, 154: 239-242.

28. Salkovskis PM, J ones DO \& Clark DM (1986). Respiratory control in treatment of panic attacks: replication and extension with concurrent measurement of behavior and $\mathrm{pCO}_{2}$. British J oumal of Psychiatry, 148: 526-532.

29. Valença $A M$, Nascimento I \& Nardi AE (2001). Smoking and panic disorder. Psychiatric Services, 52: 1105-1106.

30. West R \& Hajek P (1997). What happens to anxiety levels on giving up smoking? American J ournal of Psychiatry, 154: 1589-1592.

31. Russel MA (1989). Subjective and behavioral effects of nicotine in humans: some sources of individual variation. In: Nordberg A, Fuxe K, Holmstedt B \& Sundwall A (Editors), Progress in Brain Research. Elsevier, New York, NY, USA.

32. Maany I, Woody G \& Foulks E (1987). Nicotine and panic attacks. American J oumal of Psychiatry, 144: 252-255.

33. Smoller J W \& Tsuang MT (1998). Panic and phobic anxiety: defining phenotypes for genetic studies. American J ournal of Psychiatry, 155: 1152-1162.

34. Goodwin RD \& Hamilton SP (2001). Cigarette smoking and panic attacks: the role of neuroticism. In: New Research Abstracts. Vol. 1. American Psychiatric Press, Washington, DC, USA, 3-4.

35. Breslau N, Kilbey M \& Andreski P (1993). Vulnerability to psychopathology in nicotine-dependent smokers: an epidemiologic study of young adults. American J oumal of Psychiatry, 150: 941-946. 